\title{
Reaction behavior of oil sand in fluidized-bed pyrolysis
}

\author{
Gao Jinsen ${ }^{1}$, Xu Tao ${ }^{1,2}$, Wang Gang ${ }^{1 *}$, Zhang Angui ${ }^{1}$ and Xu Chunming ${ }^{1}$ \\ ${ }^{1}$ State Key Laboratory of Heavy Oil Processing, China University of Petroleum, Beijing 102249, China \\ ${ }^{2}$ China International United Petroleum \& Chemicals Co., Ltd., Beijing 100728, China \\ (c) China University of Petroleum (Beijing) and Springer-Verlag Berlin Heidelberg 2013
}

\begin{abstract}
The reaction behavior of oil sand from Inner Mongolia (China) were studied in a fluidizedbed pyrolysis process, and a comparative study was conducted on the properties of the liquid products obtained through fluidized-bed pyrolysis of oil sand and the native bitumen obtained by solvent extraction. The results indicated that the fluidized-bed pyrolysis, a feasible carbon rejection process, can be used to upgrade oil sand. The reaction temperature and time were found to be the key operating parameters affecting the product distribution and yields in fluidized-bed pyrolysis of oil sand. The optimal temperature was $490{ }^{\circ} \mathrm{C}$ and the most suitable reaction time was $5 \mathrm{~min}$. Under these operation conditions, the maximum yield of liquid product was $80 \mathrm{wt} \%$. In addition, the pyrolysis kinetics of oil sand at different heating rates of $5,10,20$ and $30{ }^{\circ} \mathrm{C} / \mathrm{min}$ was investigated using a thermogravimetric analyzer (TGA).
\end{abstract}

Key word: Oil sand, bitumen, fluidized-bed pyrolysis, fluidized bed, thermogravimetric analyzer, Kinetics

\section{Introduction}

The depletion of conventional oil reserves and the increasing price of crude oil are leading to the use of unconventional oil resources. Oil sands, an alternative fossil fuel (Söderbergh et al, 2007), will play an important role in the future. The worldwide recoverable oil sands are approximately $6.5 \times 10^{11}$ bbl (Zhai, 2008), about $32 \%$ of the total recoverable oil and gas resources. In China, there are plenty of undeveloped oil sands located in Inner Mongolia, Xinjiang, Qinghai and Sichuan (Niu and Hu, 1999). The shallowly buried oil sands located in the Songliao Basin of Inner Mongolia (China) are of great value for development and utilization because of their large volume as well as high bitumen contents (Jia, 2007).

Oil sand is mainly used for extracting bitumen. The bitumen from oil sand can be recovered through open-pit mining and in-situ thermal processes (Bhargava et al, 2005; Yan et al, 2009). The open-pit mining process includes the mining of oil sand and the subsequent surface processing to recover bitumen from the sand matrix. The hot water separation method was most widely used for separating and recovering bitumen (Speight, 2006; Subramanian and Hanson, 1998). However, the biggest disadvantage of the hot water separation method is that it was limited by the types of oil sands: high bitumen recovery yields can only be achieved for water-wet oil sands (Meng, 2007). Solvent extraction

*Corresponding author. email: wanggang@cup.edu.cn Received July 11, 2013 can increase the bitumen recovery of the oil-wet oil sands, but it requires a large amount of organic solvent, resulting in high treatment costs and potential environmental pollution. To overcome this problem, a more feasible alternative way is to process oil sands by a direct pyrolysis process to obtain bitumen-derived liquid products.

A lot of research has been conducted on the pyrolysis of oil sands. Most studies have been focused on obtaining liquid products in fixed beds (Meng, 2007; Meng et al, 2007), rotary kilns (Berg, 1959; Kraemer and Meresz, 1978; Taciuk, 1977; Hanson et al, 1995; 1992a; Cha et al, 1991) or fluidized-bed reactors (Cha et al, 1991; Hanson et al, 1992b; Fletcher et al, 1995; Gishler and Peterson, 1956; Nathan et al, 1969; Nathan and Grubb, 1969). Thermogravimetry is employed to investigate the effects of heating rate on pyrolysis and reaction kinetics to optimize the pyrolysis process (Li et al, 1995; Khraisha, 1999; Sonibare et al, 2003; Ma and Li, 2010). Lu et al (2008) has patented a process and apparatus for direct fluidized-bed coking of oil sands, as shown in Fig. 1. This process may improve the bitumen recovery of oil-wet oil sands with continuously feeding and good operating flexibility. Fluidized-bed pyrolysis of oil sands has a potential of producing bitumen-derived liquid products, although research on pyrolysis of oil sand is still at a laboratory scale. Therefore, the pyrolysis of oil sand from Inner Mongolia is worthy of investigation in order to widen the feedstock resources for fluidized-bed pyrolysis.

In this work, fluidized-bed pyrolysis of Inner Mongolian oil sand was investigated under different operating conditions, such as reaction temperature, 


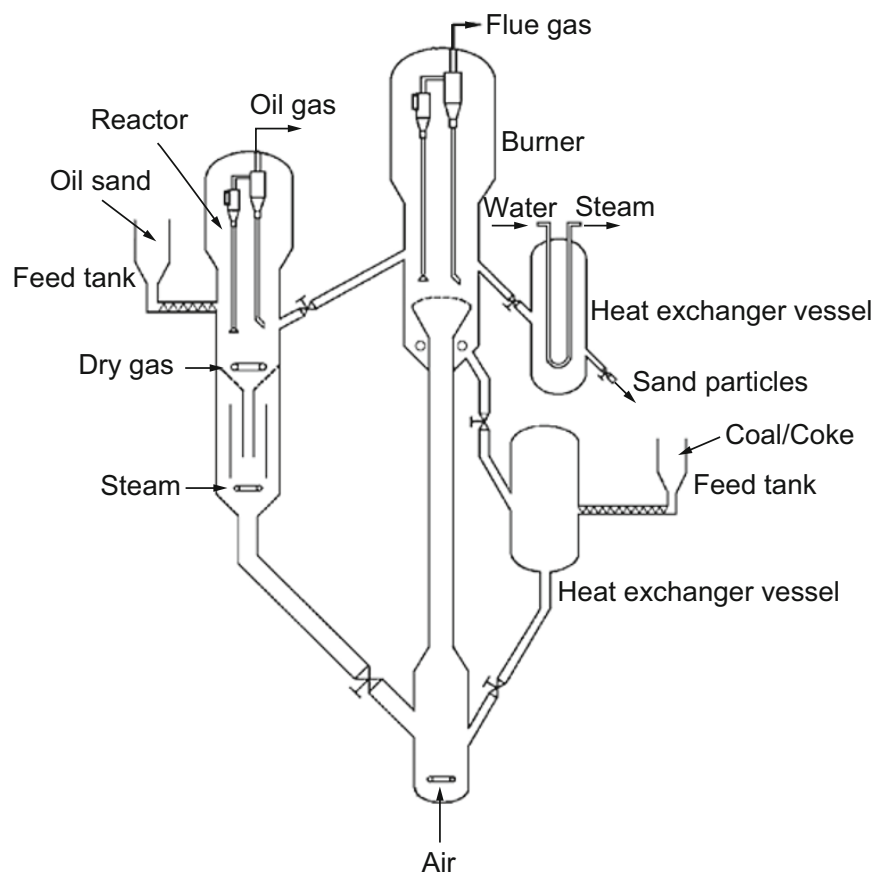

Fig. 1 Fluidized-bed coking process for oil sands

reaction time, mass ratio of water to bitumen and mass ratio of hot carrier to oil sand. Moreover, a comparative study was carried out of the properties of liquid products obtained through fluidized-bed pyrolysis of oil sand and those of native bitumen obtained by solvent extraction. The pyrolysis kinetics of Inner Mongolian oil sand was also studied using a thermogravimetric analyzer.

\section{Experimental section}

\subsection{Feedstocks and hot carrier}

The oil sand sample used in this study was from the Songliao Basin of Inner Mongolia in Northeast China. The bitumen and the water contents of the oil sand were measured by the Dean-Stark extraction method (Meng, 2007; Liang, 1992). The basic properties of oil sand are listed in Table 1 and Table 2.

Table 1 Content of bitumen and yield of oil of Inner Mongolian oil sand

\begin{tabular}{cc}
\hline Items & Results, wt \% \\
\hline Bitumen & 10.09 \\
Moisture & 14.0 \\
Sand & 75.9 \\
Oil yield of oil sand (by Fischer Assay) & \\
Oil & 8.40 \\
Gas & 1.74 \\
Water & 11.6 \\
Semi-coke & 78.3 \\
\hline
\end{tabular}

Table 2 Proximate analysis of Inner Mongolian oil sand

\begin{tabular}{cccc}
\hline Volatile, wt $\%$ & Ash, wt $\%$ & Moisture, wt $\%$ & Fixed carbon, wt $\%$ \\
\hline 11.8 & 80.2 & 7.32 & 0.66 \\
\hline
\end{tabular}

The heat carrier is the sand obtained by removing coke from the coked sand in a muffle furnace in air, and its physical properties are shown in Table 3 and Table 4.

Table 3 Composition analysis of hot carrier

\begin{tabular}{cc}
\hline Component & Content, wt $\%$ \\
\hline $\mathrm{SiO}_{2}$ & 80.0 \\
$\mathrm{Al}_{2} \mathrm{O}_{3}$ & 11.0 \\
$\mathrm{Fe}_{2} \mathrm{O}_{3}$ & 1.16 \\
$\mathrm{TiO}_{2}$ & 0.53 \\
$\mathrm{CaO}$ & 0.57 \\
$\mathrm{MgO}$ & 0.24 \\
$\mathrm{~K}_{2} \mathrm{O}$ & 3.31 \\
$\mathrm{Na}_{2} \mathrm{O}$ & 2.62 \\
$\mathrm{MnO}_{2}$ & 0.03 \\
$\mathrm{P}_{2} \mathrm{O}_{5}$ & 0.02 \\
$\mathrm{SO}_{3}$ & 0.09 \\
\hline
\end{tabular}

Table 4 Physical properties of hot carrier for fluidized-bed pyrolysis of oil sand

\begin{tabular}{lc}
\hline \multicolumn{1}{c}{ Items } & Results \\
\hline BET surface area, $\mathrm{m}^{2} / \mathrm{g}$ & 5.31 \\
Pore volume, $\mathrm{cm}^{3} / \mathrm{g}$ & 0.014 \\
Average pore diameter, $\mathrm{nm}$ & 11.1 \\
Bulk density, $\mathrm{g} / \mathrm{cm}^{3}$ & 1.20 \\
Particle density, $\mathrm{g} / \mathrm{cm}^{3}$ & 2.03 \\
Particle size distribution, wt $\%$ & \\
$<74 \mu \mathrm{m}$ & 5.17 \\
$74-130 \mu \mathrm{m}$ & 19.4 \\
$130-200 \mu \mathrm{m}$ & 42.7 \\
$200-300 \mu \mathrm{m}$ & 19.9 \\
$300-450 \mu \mathrm{m}$ & 12.8 \\
\hline
\end{tabular}

\subsection{Experimental apparatus}

Fluidized-bed pyrolysis experiments were carried out in a fluidized-bed reactor system (Meng et al, 2007) shown in Fig. 2. It was comprised of five sections: the oil sand feeder, the steam input system, the fluidized bed reactor, the temperature control system, and the products collection and separation system. The oil sand feeder was at the upper part of fluidized bed reactor. In order to prevent oil sand agglomeration due to heating during feeding, a cooling-water jacket was installed at the outside of the feeding tube to cool it. As a consolidated 


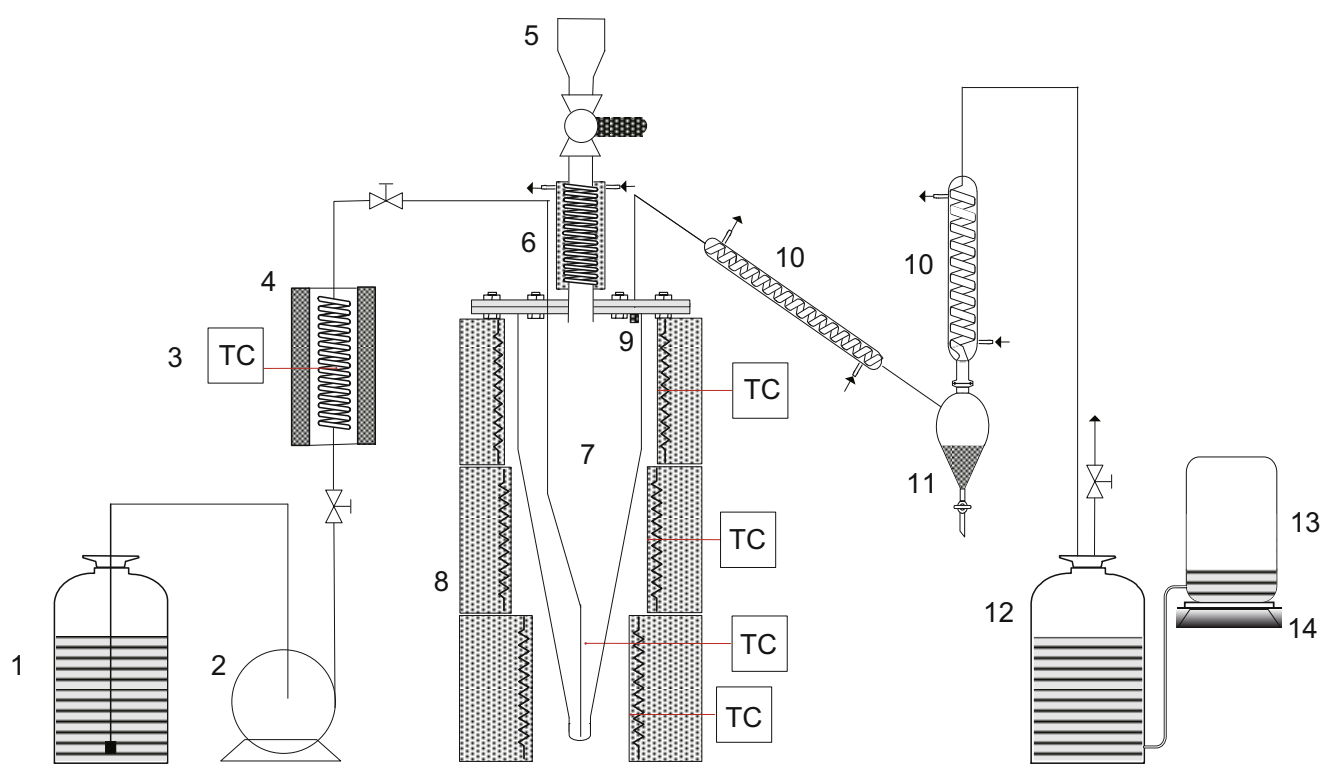

Fig. 2 Schematic diagram of fluidized-bed pyrolysis reaetor system

1-water tank; 2-water pump; 3-temperature control instruments; 4-steam furnace; 5-feeder tank; 6-cool water jacket; 7-reactor; 8-reactor furnace; 9-filter;10-condenser; 11-liquid product sampler;

12-gas collection vessel; 13 -water collection vessel; 14-electronic scales

bitumen-impregnated sandstone, the oil sand was crushed and screened prior to being fed to the reactor. Because the crushed oil sand tends to agglomerate in the feeding tank, the feeding tube and the fluidized bed reactor, it was mixed with carrier in a mass ratio of 1:1 to ensure that it would flow freely from the feeding tank into the reactor through the feeding tube. In each experiment, hot carrier (with an effective volume of about $880 \mathrm{~mL}$ ) was loaded into the reactor firstly. Distilled water was pumped into a furnace to form steam to keep the hot carrier fluidized. Once the reactor reached the set temperature, oil sand was fed into the fluidized bed reactor, where oil sand was mixed with the fluidized hot carrier, and the reaction took place. At the end of the reaction time, the heater was shut down and the reactor was quenched immediately by cold water to $350{ }^{\circ} \mathrm{C}$ to stop the reaction. Finally, the oil sand and the hot carrier were stripped for $40 \mathrm{~min}$ in order to recover the product completely. To study the pyrolysis kinetics of Inner Mongolian oil sand, a WCT-1D thermogravimetric analyzer (TGA/DSC1, METTLER TOLEDO, Switzerland) was used. During the experiments, about $40 \mathrm{mg}$ of oil sand sample was evenly spread on a ceramic crucible. The initial thermogravimetry (TGA) temperature for all the samples was set at $30{ }^{\circ} \mathrm{C}$ and the final temperature was set at $600{ }^{\circ} \mathrm{C}$. The heating rates were from $5,10,20$ to $30{ }^{\circ} \mathrm{C} / \mathrm{min}$, respectively. The tests were carried out under a nitrogen purge at a rate of $30 \mathrm{~mL} / \mathrm{min}$.

\subsection{Product analysis}

In the fluidized-bed pyrolysis experiments, the product gases were analyzed using an Agilent 6890 GC with Chem Station to determine the volume composition. The state equation for ideal gases was used to convert the volume data to mass percentages for the material balance. The condensed liquid products were collected and centrifugated at 3,000 r/ min for $10 \mathrm{~min}$. The upper liquid was weighed and analyzed with the simulated distillation gas chromatogram to obtain the weight percentages of gasoline $\left(\mathrm{C}_{5}-200{ }^{\circ} \mathrm{C}\right)$, diesel $(200-350$ $\left.{ }^{\circ} \mathrm{C}\right)$ and heavy oil $\left(>350{ }^{\circ} \mathrm{C}\right)$. The coke on the hot carrier and coked sand were measured with a coke analyzer.

\section{Results and discussion}

\subsection{Fluidized-bed thermal reaction}

The effects of reaction parameters on the product distribution and yields were investigated, and the operating conditions for the main pyrolysis experiments are listed in Table 5, where the mass ratio of water to bitumen is defined as the ratio of water input per minute to total bitumen fed to the reactor, liquid product is defined as the sum of gasoline, diesel and heavy oil, and the feedstock conversion refers to the sum of the yields of dry gas, liquid petroleum gas (LPG), gasoline, diesel and coke.

Table 5 Operating conditions for fluidized-bed pyrolysis of oil sand

\begin{tabular}{cc}
\hline Items & Data \\
\hline Temperature of reactor, ${ }^{\circ} \mathrm{C}$ & $450-530$ \\
Reactor time, min & $2-10$ \\
Temperature of steam furnace, ${ }^{\circ} \mathrm{C}$ & 350 \\
Water inflow, $\mathrm{mL} / \mathrm{min}$ & $1.0-5.0$ \\
Loaded hot carrier, $\mathrm{g}$ & $50-150$ \\
Mass ratio of hot carrier to oil sand & $2-6$ \\
Stripping time, min & 40 \\
\hline
\end{tabular}

\subsubsection{Effect of reaction temperature}

In order to obtain the optimal temperature for oil sand fluidized-bed pyrolysis, experiments at temperatures from 
470 to $530{ }^{\circ} \mathrm{C}$ were conducted with a fixed reaction time of 5 min, water to bitumen mass ratio of 0.4 and hot carrier to oil sand mass ratio of $2: 1$. The experimental data are shown in Fig. 3. All the yields are presented as weight percent of total bitumen on oil sand fed into the reactor.

Fig. 3 showed that with increasing temperature, both the feedstock conversion and the yields of dry gas, LPG, gasoline, and light oil increased, while the yield of heavy oil decreased significantly. High reaction temperature means harsh conditions and high pyrolysis extent. Since dry gas was the end product of thermal reaction, its yield increased with an increase of reaction temperature. LPG, gasoline, diesel and heavy oil were intermediate products, their yields decreased after reaching a maximum value

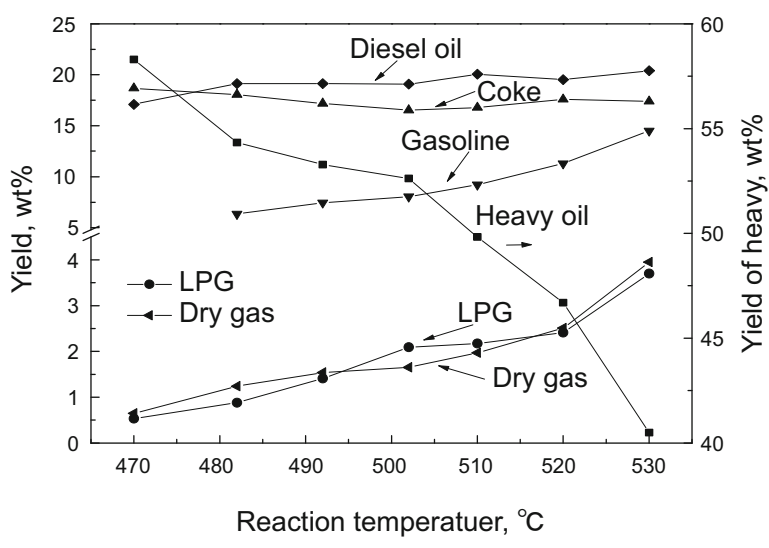

(a)

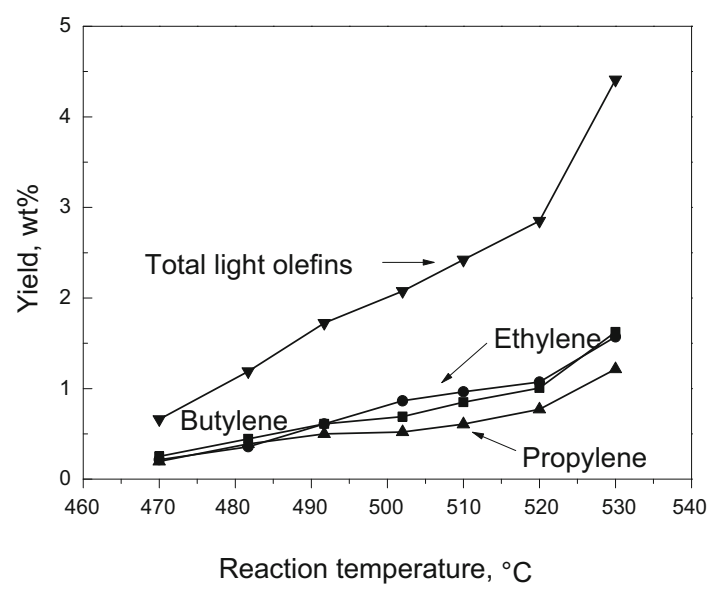

(c) because of secondary reactions. The maximum yields of gasoline and LPG were not observed because the reaction temperature range was relatively narrow. The yield of diesel passed through a maximum at about 510 ${ }^{\circ} \mathrm{C}$ although the change of diesel yield was relatively small. In this work, the yield of heavy oil decreased, along with the increasing yields of dry gas, LPG and gasoline, with increasing temperature due to harsher conditions of thermal cracking. The yield of coke on the hot carrier showed a minimal value at $500{ }^{\circ} \mathrm{C}$. The maximum yield $(80 \mathrm{wt} \%)$ of the liquid product was obtained at a reaction temperature of $490{ }^{\circ} \mathrm{C}$. At temperatures above $490{ }^{\circ} \mathrm{C}$ the total liquid product decreased, due to part of the heavy oil being converted into dry gas and LPG.

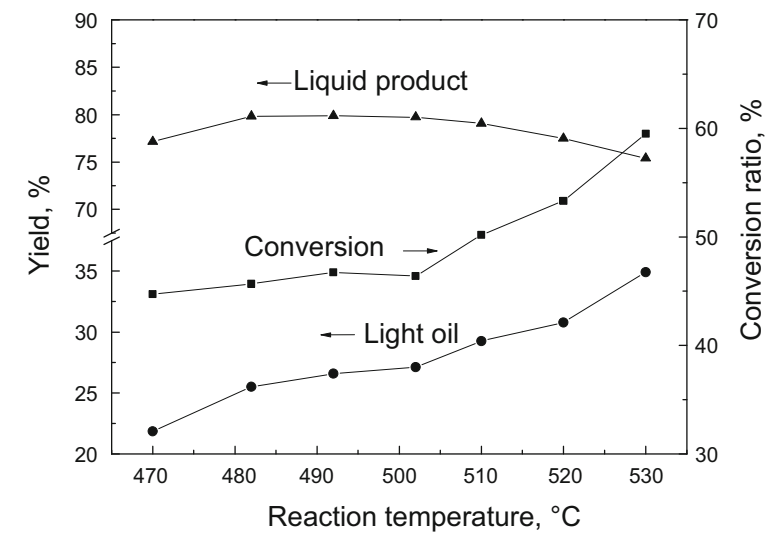

(b)

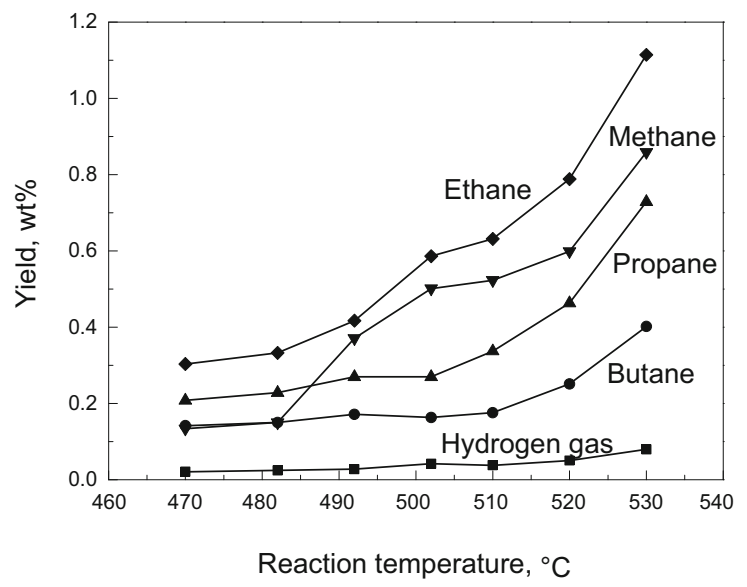

(d)

Fig. 3 Effect of reaction temperature on product distribution and yields (reaction time, $5 \mathrm{~min}$; mass ratio of water to bitumen, 0.4 ; mass ratio of hot carrier to oil sand, $2: 1$ )

In fluidized-bed pyrolysis of oil sands, bitumen with high-boiling components was directly converted at high temperatures on the surface of oil sand into low boiling liquid products, and the reaction followed free radical mechanisms, and mainly took place on the hot carrier surface and spaces between the hot carrier particles. The heavy hydrocarbon molecules of bitumen cracked into lighter hydrocarbons, such as dry gas, LPG, gasoline, diesel and heavy oil, which volatized and passed from the reactor. Being intermediate products, gasoline, diesel and heavy oil can undergo secondary reactions such as cracking and polymerization.
Coke is produced and deposits on the hot carrier. On an industrial scale, the oil and gas would be recovered in to be used as a feedstock of subsequent processing steps such as catalytic cracking and hydrotreating. The objective of the fluidized-bed pyrolysis was to obtain the maximum liquid product from oil sand. The maximum yield $(80 \mathrm{wt} \%)$ of liquid product was obtained at $490{ }^{\circ} \mathrm{C}$, which was the optimal reaction temperature.

The variation of the yields of light olefins, light alkanes and hydrogen with reaction temperature is shown in Fig. 3(c) and Fig. 3(d). The yields of light olefins, light alkanes 
and hydrogen increased monotonically with increasing temperature. However, their yields were low, and will not be discussed further. Light olefins, light alkanes and hydrogen were by-products of the fluidized-bed pyrolysis of oil sands, and they would reduce the yields of the liquid products. Increasing the reaction temperature would intensify the reaction of pyrolysis and would increase the by-product yields significantly.

\subsubsection{Effect of reaction time}

The effect of the reaction time on product distribution and yields was investigated at $500{ }^{\circ} \mathrm{C}$, and mass ratios of water to bitumen and hot carrier to oil sand of 0.4 and $2: 1$, respectively, for reaction times from 2-10 $\mathrm{min}$. The results are shown in Fig. 4.

The yields of dry gas, LPG, gasoline, diesel oil and heavy oil increased with increasing reaction time in the range of 2 to $5 \mathrm{~min}$. No further increase/change was observed with reaction times longer than $5 \mathrm{~min}$, suggesting that the reaction was almost completed within $5 \mathrm{~min}$. Longer reaction time means more time for the pyrolysis of hydrocarbons. The optimal reaction time was determined to be $5 \mathrm{~min}$.

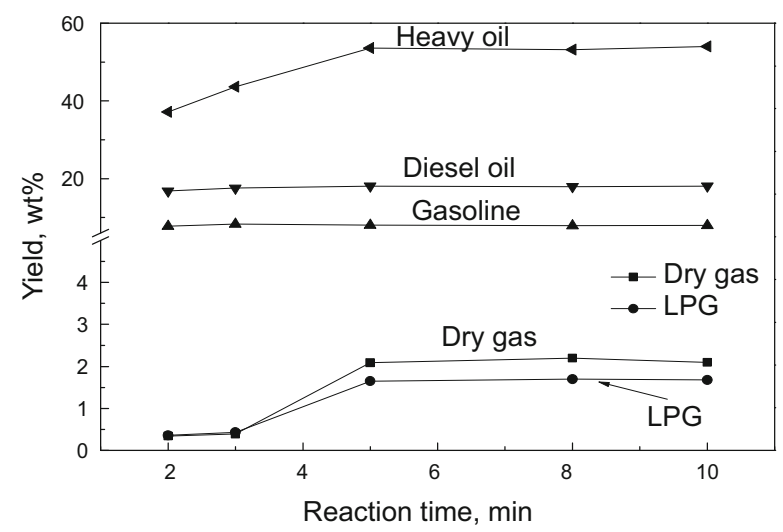

(a)

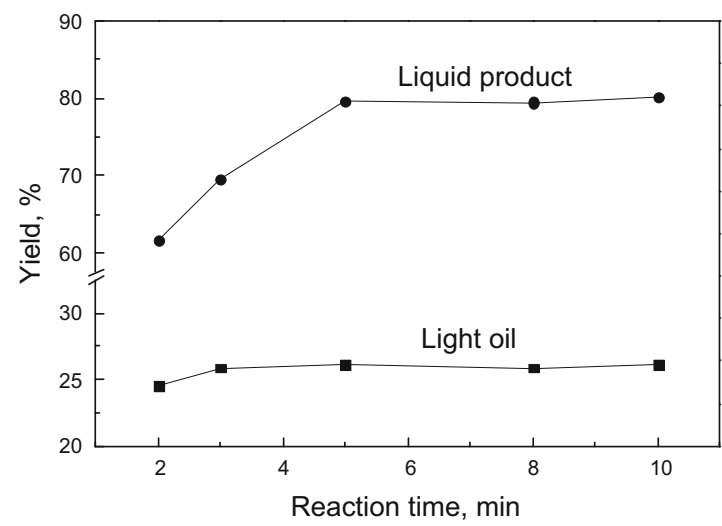

(b)

Fig. 4 Effect of reaction time on product distribution and yields (reaction temperature, $500{ }^{\circ} \mathrm{C}$; mass ratio of water to bitumen, 0.4 ; mass ratio of hot carrier to oil sand, $2: 1$ )

\subsubsection{Effect of mass ratio of water to bitumen}

Under the conditions of the reaction temperature, the reaction time and the mass ratio of hot carrier to oil sand of $500{ }^{\circ} \mathrm{C}, 5 \mathrm{~min}$, and $2: 1$, respectively, the effect of mass ratio of water to bitumen fed to the fluidized bed reactor on the product distribution and yields was investigated in the range of 0.2 to 0.6 . The distribution and yields of the products as a function of mass ratio of water to bitumen are shown in Fig. 5.

It can be seen that with increasing mass ratio of water to bitumen, the feedstock conversion, the yields of dry gas,
LPG, gasoline and light oil decreased slightly while the yield of heavy oil increased marginally. The yield of diesel varied linearly while the yield of coke was unchanged. The yield of the liquid product increased with increasing mass ratio of water to bitumen from 0.2 to 0.4 , and then remained almost unchanged from 0.4 to 0.6 .

Steam can restrain condensation or polymerization of hydrocarbons in fluidized-bed pyrolysis of oil sand. Therefore, the increase of the mass ratio of water to bitumen can prevent coke deposition on the hot carrier and reduce
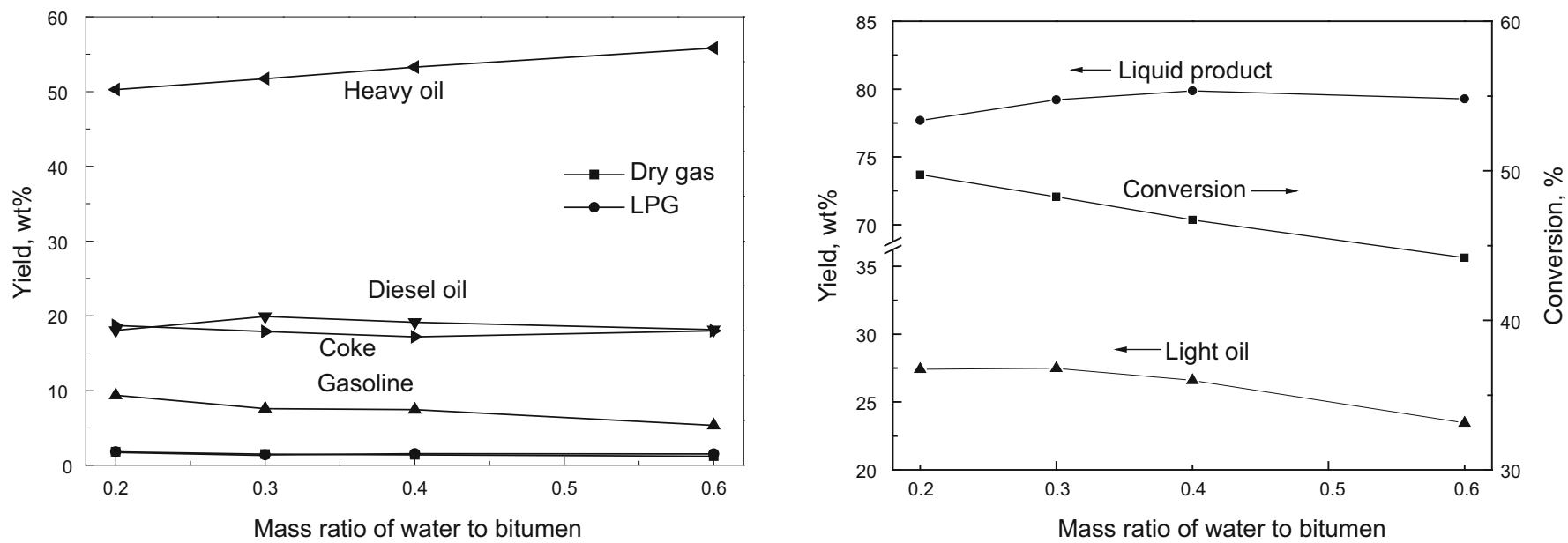

Fig. 5 Effect of mass ratio of water to bitumen on product distribution and yields (reaction temperature, $490{ }^{\circ} \mathrm{C}$; reaction time, $5 \mathrm{~min}$; mass ratio of hot carrier to oil sand, $2: 1)$ 
the yield of coke. However, because the coke deposition was very low, it was difficult to evaluate the effect of mass ratio of water to bitumen on coke yield. In addition, a large mass ratio of water to bitumen means a short residence time for oil. This will result in uncompleted pyrolysis, and prevent the secondary cracking of oil in the reactor, subsequently, leading to low feedstock conversion and an increased yield of heavy oil. Considering the energy consumption and economic

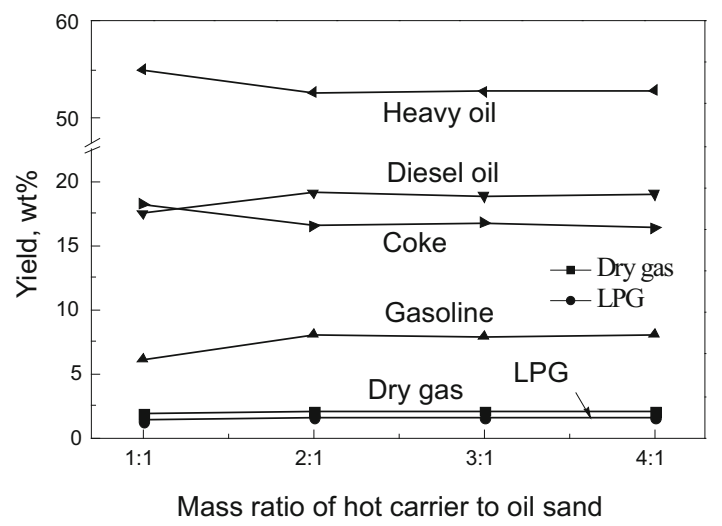

(a) returns, the optimal mass ratio of water to bitumen was determined as around 0.4 .

\subsubsection{Effect of mass ratio of hot carrier to oil sand}

The effect of the mass ratio of hot carrier to oil sand on product distribution and yields was investigated in the range of $1: 1$ to $4: 1$ under the reaction conditions of temperature of $500{ }^{\circ} \mathrm{C}$, the reaction time of $5 \mathrm{~min}$ and the mass ratio of water to bitumen of 0.4 . The experimental data are shown in Fig. 6.

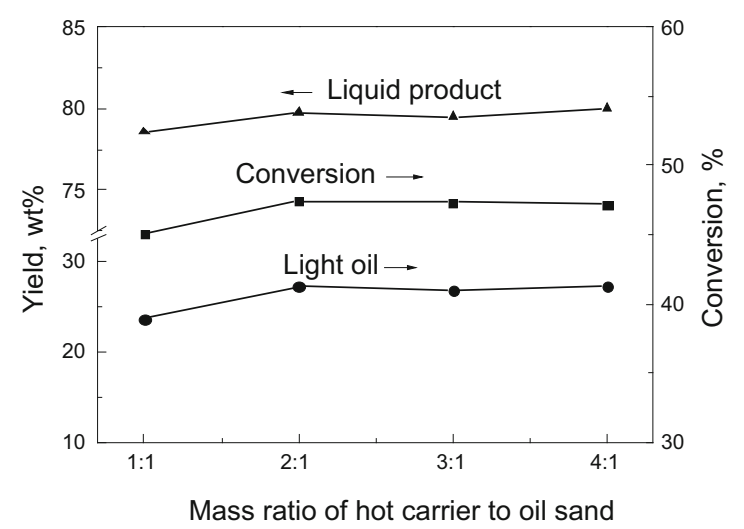

(b)

Fig. 6 Effect of mass ratio of hot carrier to oil sand on product distribution and yields (reaction temperature, $500{ }^{\circ} \mathrm{C}$; reaction time, $5 \mathrm{~min}$; mass ratio of water to bitumen, 0.4 )

Fig. 6 showed that with increasing mass ratio of hot carrier to oil sand, the feedstock conversion, the yields of dry gas, LPG, gasoline, diesel oil, light oil, liquid product increased slightly, while the yield of heavy oil decreased slightly. As the mass ratio of hot carrier to oil sand increased, there were more contacts between hot carrier and oil sand. The fluidized state and heat transfer were improved and the yield of products of low molecular weights increased. However, the product yield varied very slightly with increasing mass ratio of hot carrier to oil sand, hence it was difficult to investigate the variation of product yields as a function of the mass ratio of hot carrier to oil sand in this study. In the fluidized-bed pyrolysis process, a larger mass ratio of hot carrier to oil sand would bring more energy to the reaction system, hence accelerate the thermal cracking reactions. Considering the energy consumption, handling capacity and the economic returns, In this work, the optimal mass ratio of hot carrier to oil sand was determined to be $2: 1$.

\subsection{Comparative study for product between organic solvent extraction and fluidized-bed thermal reaction}

It is important to determine the extent of upgrading of the liquid product in comparison to the original bitumen, because the quality of the liquid product is the key factor in the selection of subsequent processing steps for upgrading and/or refining the liquid product. A comparative study was conducted on the properties of the liquid products obtained through the fluidized-bed pyrolysis and the native bitumen obtained by organic solvent extraction. The native bitumen sample was obtained by solvent extraction of crushed oil sand with toluene in a Soxhlet extraction apparatus, and then the solvent was stripped from the solvent-bitumen solution under vacuum to obtain the native bitumen. The liquid product was obtained through the fluidized-bed pyrolysis at a reaction temperature of $500{ }^{\circ} \mathrm{C}$, a reaction time of $5 \mathrm{~min}$, water to bitumen mass ratio of 0.4 and hot carrier to oil sand mass ratio of 2:1. Detailed properties of the native bitumen and the liquid product are listed in Table 6 .

The density, viscosity and Conradson carbon residue of the liquid product were markedly decreased when compared to those of the native bitumen. The density decreased from $1.08 \mathrm{~g} / \mathrm{cm}^{3}$ for the Inner Mongolian native bitumen to $0.96 \mathrm{~g} /$ $\mathrm{cm}^{3}$ for the liquid product. The viscosity of the liquid product decreased by several orders of magnitude compared with that of the native bitumen at the same temperature. The mass percent of $\mathrm{C}$ and $\mathrm{H}$ of the liquid product was higher, while the mass percent of $\mathrm{S}, \mathrm{N}$ and $\mathrm{O}$ was much lower, than that of the native bitumen. The amounts of hetero atoms $(\mathrm{S}, \mathrm{N}$ and $\mathrm{O}$ ) and trace metals ( $\mathrm{Ni}$ and $\mathrm{V}$ ) were substantially reduced in the liquid products, indicating that most of the hetero atoms and trace metals were deposited on the hot carrier. The Conradson carbon residue of the liquid product $(2.16 \mathrm{wt} \%)$ was significantly lower than that of the native bitumen $(16.5 \mathrm{wt} \%)$. The amount of preferred components (saturates and aromatics) in the product liquid were increased at the expense of resin and asphaltenes. These results indicated that the fluidized-bed pyrolysis is a feasible carbon rejection process to obtain high quality liquid product from oil sand. In addition, the liquid product exhibited a significant shift in the boiling range compared with the native bitumen: the vacuum residue fraction $\left(>500{ }^{\circ} \mathrm{C}\right)$ was reduced from $88 \mathrm{wt} \%$ to $28.6 \mathrm{wt} \%$, the vacuum gas oil fraction increased from $10.8 \mathrm{wt} \%$ to $41.1 \mathrm{wt} \%$, the diesel fraction increased from $1.2 \mathrm{wt} \%$ to $23.2 \mathrm{wt} . \%$, and the gasoline fraction was increased from $0 \mathrm{wt} \%$ 
Table 6 Physical and chemical properties of native bitumen and liquid product from pyrolysis of oil sand

\begin{tabular}{|c|c|c|}
\hline Items & Native bitumen & Liquid product \\
\hline Density at $20^{\circ} \mathrm{C}, \mathrm{g} / \mathrm{cm}^{3}$ & 1.084 & 0.963 \\
\hline Viscosity at $20{ }^{\circ} \mathrm{C}, \mathrm{mPa} \cdot \mathrm{s}$ & $>50000$ & 38.3 \\
\hline Conradson carbon residue, wt $\%$ & 16.55 & 2.16 \\
\hline \multicolumn{3}{|l|}{ Elemental analysis, wt $\%$} \\
\hline $\mathrm{C}$ & 83.8 & 86.6 \\
\hline $\mathrm{H}$ & 11.4 & 12.2 \\
\hline S & 0.35 & 0.126 \\
\hline $\mathrm{N}$ & 0.86 & 0.136 \\
\hline $\mathrm{O}$ & 3.57 & 0.888 \\
\hline $\mathrm{H} / \mathrm{C}$ atomic ratio & 1.63 & 1.70 \\
\hline Molecular weight, $\mathrm{g} / \mathrm{mol}$ & 1341 & 316 \\
\hline $\mathrm{Ni}, \mathrm{ng} / \mathrm{g}$ & 4639 & 57.8 \\
\hline $\mathrm{V}, \mathrm{ng} / \mathrm{g}$ & 6904 & 94.7 \\
\hline \multicolumn{3}{|l|}{ SARA analysis } \\
\hline Saturated, wt $\%$ & 14.1 & 67.0 \\
\hline Aromatics, wt $\%$ & 8.87 & 22.2 \\
\hline Resin, wt $\%$ & 18.3 & 10.1 \\
\hline Asphaltene, wt $\%$ & 58.7 & 0.73 \\
\hline \multicolumn{3}{|l|}{ Simulated distillation, wt $\%$} \\
\hline IBP- $200{ }^{\circ} \mathrm{C}$ & 0 & 7.3 \\
\hline $200-350^{\circ} \mathrm{C}$ & 1.2 & 23.2 \\
\hline $350-500^{\circ} \mathrm{C}$ & 10.8 & 41.1 \\
\hline $500-611.6^{\circ} \mathrm{C}$ & 51.1 & 28.6 \\
\hline
\end{tabular}

to $7.3 \mathrm{wt} \%$. As a result, the quality of liquid product from pyrolysis of oil sand was significantly improved compared with that of the native bitumen, and the liquid product would be an excellent feedstock for further processing in a refinery. Pyrolysis of oil sand can obtain high quality liquid products; it had more advantages than the organic solvent extraction of bitumen-sand.

\subsection{Kinetic analysis of thermal reaction}

Thermal analysis of oil sand can help understanding the pyrolysis of oil sand, and the behavior of oil sand can be predicted with a high degree of certainty over a wide range of operating conditions. In this study, the effects of various conditions, such as temperature and heating rates, on the reaction behavior and kinetic parameters of the Inner Mongolian oil sand were investigated.

\subsubsection{Pyrolysis behavior}

The thermogravimetry (TG) and the differential thermogravimetry (DTG) data of the oil sand at different heating rates are shown in Fig. 7 and Fig. 8. It can be seen that the weight-loss process of the oil sand can be separated into three steps: the vaporization of moisture in the samples below $150{ }^{\circ} \mathrm{C}$; the volatilization of relatively light hydrocarbons in the oil sand from 150 to about $350{ }^{\circ} \mathrm{C}$, and the cracking of the relatively heavy hydrocarbons from 350 to $550{ }^{\circ} \mathrm{C}$, when a series of complex reactions took place due to the heavy hydrocarbons being heated and cracked into smaller molecules, including the gaseous hydrocarbons and oil. With an increase of the heating rate, the TG curves and the peaks on the DTG curves shifted to a higher temperature region and the final weight loss tended to reduce. These behaviors could be explained on the basis of heat transfer and diffusion. The higher heating rate means harsher conditions, which would lead to the pyrolysis of some hydrocarbons and the formation of coke at higher temperature. Therefore, the final weight loss decreased. The results in Fig. 9 showed no change in conversion at temperature higher than $550{ }^{\circ} \mathrm{C}$ indicating that the pyrolysis was completed at about $550{ }^{\circ} \mathrm{C}$.

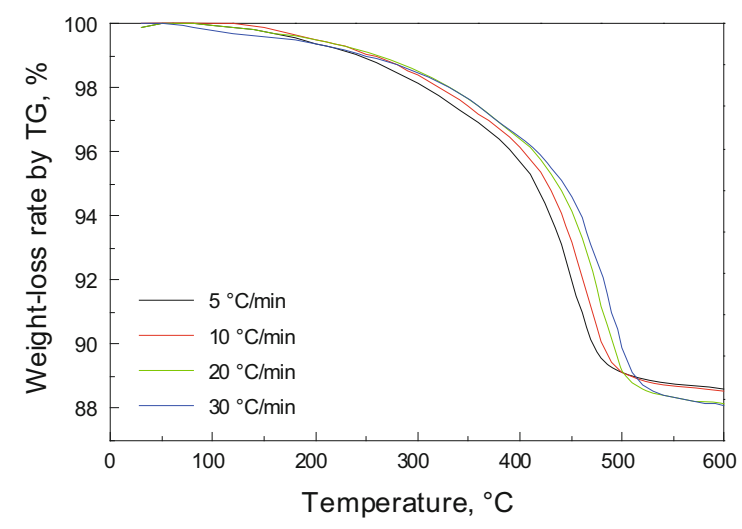

Fig. 7 TG curves of the oil sand at different heating rates

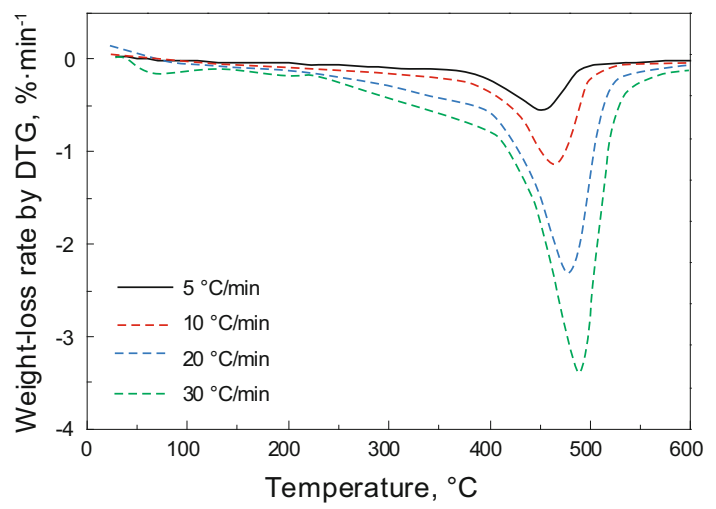

Fig. 8 DTG curves of the oil sand at different heating rates

\subsubsection{Kinetic analysis of pyrolysis of oil sand}

The kinetics of thermal reactions of oil sand ( $\mathrm{Li}$ and Yue, 2003; 2004; Jaber and Probert, 2000; Wang et al, 2009) can be calculated from the TG data, using the Arrhenius expression to correlate of weight-loss rate with temperature. The kinetic parameters, activation energy, and pre-exponential factor for oil sand pyrolysis were determined by the CoatsRedfern method (Li and Yue, 2003; 2004; Jaber and Probert, 2000; Wang et al, 2009). Generally, oil sand pyrolysis can be regarded as a first-order reaction ( $\mathrm{Li}$ et al, 1995; Khraisha, 1999; Sonibare et al, 2003; Ma and Li, 2010). The overall conversion of bitumen in oil sand can be represented as follows: 


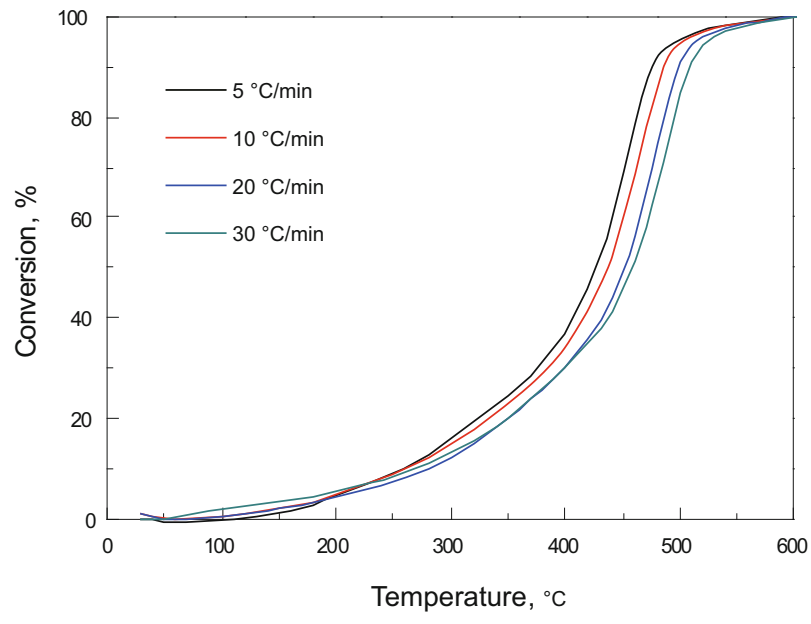

Fig. 9 Conversion versus temperature for oil sand at different heating rates

Bitumen $\rightarrow$ gas + oil + coke

Oil sand pyrolysis can be described using the following reaction model:

$$
\frac{\mathrm{d} x}{\mathrm{~d} t}=A \exp \left(-\frac{E}{R T}\right)(1-x)
$$

where $t$ is the pyrolysis time, $A$ is the pre-exponential factor, $E$ is the activation energy, $R$ is the gas constant, $T$ is the absolute temperature, $x$ is the weight loss fraction or pyrolysis at temperature $T$ or time $t$ (as shown in Fig. 9), and can be calculated by

$$
x=\frac{m_{0}-m_{t}}{m_{0}-m_{f}}
$$

where $m_{0}$ is the initial mass of the oil sand sample, $\mathrm{m}_{t}$ is the mass of oil sand at temperature $T$ or time $t, m_{f}$ is final mass of oil sand at the final temperature. For a constant heating rate, $\beta$, during pyrolysis, $\beta=\mathrm{d} T / \mathrm{d} t$, rearranging Eq.(1) using the CoatsRedfern method and the Eq.(3) can be obtained:

$$
\ln \left[\frac{-\ln (1-x)}{T^{2}}\right]=\ln \left[\frac{A R}{\beta E}\left(1-\frac{2 R T}{E}\right)\right]-\frac{E}{R T}
$$

For most values of $E$ and $T$, the expression $\ln [A R /$ $\beta E(1-2 R T / E)]$ in Eq.(3) could be considered as a constant, then the linear regression of $\ln \left[-\ln (1-x) / T^{2}\right]$ as a function of $1 / T$ will determine the apparent activation energy $E$ and frequency factor $A$ for a specific heating rate $(\beta)$. Table 7 and Table 8 show the kinetic parameters of the oil sand desorption and pyrolysis at different heating rates. As shown in Table 7 and Table 8, all the regression coefficients were greater than 0.99 . These results indicate that it was reasonable to use Coats-Redfern method to describe the oil sand desorption and pyrolysis with a first-order reaction model. The oil sand desorption stage with lower activation energy is a physical process. The activation energy of pyrolysis increased from $111 \mathrm{~kJ} / \mathrm{mol}$ to $139 \mathrm{~kJ} / \mathrm{mol}$ as the heating rates increasing from 5 to $30{ }^{\circ} \mathrm{C} / \mathrm{min}$. This is assigned to the combined effects of the heat transfer at different heating rates and kinetics of the thermal reaction, resulting in delayed effects of the thermal reaction.
Table 7 Kinetic results of oil sand

\begin{tabular}{ccccc}
\hline $\begin{array}{c}\text { Heating rate } \\
{ }^{\circ} \mathrm{C} / \mathrm{min}\end{array}$ & $\begin{array}{c}\text { Temperature } \\
{ }^{\circ} \mathrm{C}\end{array}$ & $\begin{array}{c}\text { Activation } \\
\text { energy }(E) \\
\mathrm{kJ} / \mathrm{mol}\end{array}$ & $\begin{array}{c}\text { Pre-exponential } \\
\text { factor }(A) \\
\min ^{-1}\end{array}$ & $\begin{array}{c}\text { Regression } \\
\text { coefficient }\end{array}$ \\
\hline 5 & $198-347$ & 17.4 & 0.8332 & 0.99909 \\
10 & $201-355$ & 18.8 & 1.5176 & 0.99934 \\
20 & $207-365$ & 18.8 & 1.7662 & 0.99982 \\
30 & $211-372$ & 20.3 & 0.8150 & 0.99978 \\
\hline
\end{tabular}

Table 8 Kinetic results of oil sand thermal reaction

\begin{tabular}{ccccc}
\hline $\begin{array}{c}\text { Heating rate } \\
{ }^{\circ} \mathrm{C} / \mathrm{min}\end{array}$ & $\begin{array}{c}\text { Temperature } \\
{ }^{\circ} \mathrm{C}\end{array}$ & $\begin{array}{c}\text { Activation } \\
\text { energy }(E) \\
\mathrm{kJ} / \mathrm{mol}\end{array}$ & $\begin{array}{c}\text { Pre-exponential } \\
\text { factor }(A) \\
\min ^{-1}\end{array}$ & $\begin{array}{c}\text { Regression } \\
\text { coefficient }\end{array}$ \\
\hline 5 & $440-472$ & 111.1 & $1.71 \times 10^{7}$ & 0.99845 \\
10 & $460-490$ & 121.9 & $1.58 \times 10^{8}$ & 0.99941 \\
20 & $470-500$ & 130.7 & $9.23 \times 10^{8}$ & 0.99971 \\
30 & $485-510$ & 139.4 & $3.84 \times 10^{9}$ & 0.99882 \\
\hline
\end{tabular}

\section{Conclusions}

The obtained results indicate that fluidized-bed pyrolysis of oil sands is a feasible process for the production of an upgraded bitumen-derived liquid from Inner Mongolian oil sand. The reaction temperature and the reaction time of fluidized-bed pyrolysis were the key parameters that affected the product distribution and yields in the fluidized bed reactor. The optimal reaction temperature of $490{ }^{\circ} \mathrm{C}$ and reaction time of 5 min were determined. At the optimal operation conditions, the maximum liquid yield, $80 \mathrm{wt} \%$, was obtained. The quality of the liquid product from pyrolysis of oil sand has been significantly improved compared to that of the native bitumen, and it would be an excellent feedstock for further processing in a refinery.

The weight loss process of the oil sand can be divided into three steps: the first step is below $150{ }^{\circ} \mathrm{C}$, the main reaction process in this stage is the removal of moisture from the oil sand. The second step is from 150 to $350{ }^{\circ} \mathrm{C}$, where the light hydrocarbons volatilize. The third step is between 350 and $500{ }^{\circ} \mathrm{C}$, where relatively heavy hydrocarbons pyrolyse. At higher heating rates, the pyrolysis occurred in the higher temperature region and had almost finished when the temperature reached $550{ }^{\circ} \mathrm{C}$. As the heating rate increased, the TG curves and the peaks on the DTG curves shifted to a higher temperature region and the final weight loss trended lower. The pyrolysis of oil sand can be described using firstorder reaction model and the activation energy increased from 111.1 to $139.4 \mathrm{~kJ} / \mathrm{mol}$ with an increase of the heating rate from 5 to $30{ }^{\circ} \mathrm{C} / \mathrm{min}$, respectively.

\section{Acknowledgements}

The authors acknowledge the financial support provided by the National Science Foundation of China (21176252) and the China National Petroleum Science Research Program (2011B-2404-01). 


\section{References}

Berg C H O. Tar Sand Distillation Process and Apparatus. US Patent 2905595. 1959

Bhargava S, Awaja F and Subasinghe N D. Characterisation of some Australian oil shale using thermal, X-ray and IR techniques. Fuel. 2005. 84(6): 707-715

Cha S, Hanson F V, Longstaff D C, et al. Pyrolysis of bitumen impregnated sandstones: a comparison of fluidized-bed and rotary kiln reactors. Fuel. 1991. 70(11): 1357-1361

Fletcher J V, Deo M D and Hanson F V. Fluidized bed pyrolysis of a Uinta Basin oil sand. Fuel. 1995. 75(3): 311-316

Gishler P E and Peterson W S. Treatment of Bituminous Sand. Canadian Patent CA 530920. 1956

Hanson F V, Cha S M, Deo M D, et al. Pyrolysis of oil sands from the Whiterocks deposit in a rotary kiln. Fuel. 1992a. 71(12): 1455-1563

Hanson F V, Dorius J C, Utley J K, et al. The application of compoundtype analyses to the correlation of product distributions and yields from the fluidized-bed pyrolysis of oil sands. Fuel. 1992b. 71(12): 1365-1372

Hanson F V, Fletcher J V and Zheng H. Performance of auger-type dry materials feeders when feeding oil sands. Fuel Process. Technol. 1995. 41(3): 289-304

Jaber J O and Probert S D. Non-isothermal thermogravimetry and decomposition kinetics of two Jordanian oil-shales under different processing conditions. Fuel Process. Technol. 2000. 63(1): 57-70

Jia C Z. Estimation Methods for Resources and Reserves of Oil Sands. Beijing: Petroleum Industry Press. 2007. 26-80 (in Chinese)

Khraisha Y H. Study of extraction and pyrolysis of Jordan Tar sand. Int. J. Energy Res. 1999. 23(10): 833-839

Kraemer P and Meresz O. Rotary Separating and Extracting Devices. US Patent 4098648. 1978

Li S Y and Yue C T. Study of different kinetic models for oil shale pyrolysis. Fuel Process. Technol. 2004. 85(1): 51-61

Li S Y and Yue C T. Study of pyrolysis kinetics of oil shale. Fuel. 2003. 82(3): $337-342$

Li S Y, Wang J Q, Tan H P, et al. Study of extraction and pyrolysis of Chinese oil sands. Fuel. 1995. 74(8): 1191-1193

Liang W J. AOSTRA Technical Handbook on Oil Sands, Bitumens, and Heavy Oils. Beijing: China University of Petroleum Press. 1992. 34-
35 (in Chinese)

Lu C X, Xu C M, Li S Y, et al. A Process and Apparatus of Direct Fluid Coking for Oil Sands. China Patent CN 101358134A. 2008

Ma Y and Li S Y. Study of characteristics and kinetics of oil sand pyrolysis. Energy fuel. 2010. 24(3): 1844-1847

Meng M, Hu H Q, Zhang Q M, et al. Pyrolysis behaviors of Tumuji oil sand by thermogravimetry (TG) and in a fixed bed reactor. Energy Fuels. 2007. 21(4): 2245-2249

Meng M. Extraction of organic substances from Tumuji oil sand. Ph. D. Dissertation. Dalian University of Technology, Dalian, China. 2007 (in Chinese)

Nathan M F and Grubb G C. Fluid Process Useful in the Recovery of Hydrocarbons from Tar Sands. Canadian Patent CA 819100. 1969

Nathan M F, Skaperdas G T and Grubb G C. Fluid Coking of Tar Sands. Canadian Patent CA 823186. 1969

Niu J Y and Hu J Y. Formation and distribution of heavy oil and tar sands in China. Mar. Pet. Geol. 1999. 16(1): 85-95

Söderbergh B, Robelius F and Aleklett K. A crash programme scenario for the Canadian oil sands industry. Energy Policy. 2007. 35(3): 1931-1947

Sonibare O O, Egashira R and Adedosu T A. Thermo-oxidative reactions of Nigerian oil sand bitumen. Thermochim. Acta. 2003. 405(2): 195205

Speight J G. The Chemistry and Technology of Petroleum (4th ed). Boca Raton, FL: CRC Press. 2006

Subramanian M and Hanson F V. Supercritical fluid extraction of bitumens from Utah oil sands. Fuel Process. Technol. 1998. 55(1): 35-53

Taciuk W. Process for Thermal Cracking a Heavy Hydrocarbon. US Patent 4180455. 1977

Wang Q, Wang H G, Sun B Z, et al. Interactions between oil shale and its semi-coke during co-combustion. Fuel. 2009. 88(8): 1520-1529

Yan J W, Jiang X M and Han Xiangxin. Study on the characteristics of the oil shale and shale char mixture pyrolysis. Energy Fuels. 2009. 23(12): 5792-5797

Zhai G M. Speculations on the exploration and development of unconventional hydrocarbon resources. Natural Gas Industry. 2008. 28(12): 1-3 (in Chinese)

(Edited by Zhu Xiuqin) 